\title{
Cold Tolerance of Blueberry Genotypes Throughout the Dormant Period from Acclimation to Deacclimation
}

\author{
Lisa J. Rowland ${ }^{1}$ and Elizabeth L. Ogden \\ U.S. Department of Agriculture, Agricultural Research Service, Genetic Improvement of Fruits and Vegetables \\ Laboratory, Building 010A, BARC-West, 10300 Baltimore Avenue, Beltsville, MD 20705

\begin{abstract}
Mark K. Ehlenfeldt 125A Lake Oswego Road, Chatsworth, NJ 08019
\end{abstract} \\ U.S. Department of Agriculture, Agricultural Research Service, Blueberry and Cranberry Research Center,
}

\author{
Rajeev Arora \\ Iowa State University, Department of Horticulture, Ames, IA 50011
}

\begin{abstract}
Additional index words. cold acclimation, cold hardiness, dehardening, freezing tolerance, spring frost tolerance, Vaccinium
Abstract. Cold hardiness in woody perennials is determined by complex interacting factors: the timing and rate of cold acclimation; the maximum level of cold tolerance attained; the maintenance of cold tolerance during the winter; and the rate of loss of cold tolerance or deacclimation on resumption of spring growth. For highbush blueberry, the degree of winter freezing tolerance and susceptibility to spring frosts have been identified as the most important genetic limitations of current cultivars. Depending on the winter and the location, both winter freezes and spring frosts can cause damage to floral buds or flowers resulting in substantial losses in yield. To identify genotypes that are particularly slow or late to deacclimate and thus may be useful in breeding for spring frost-tolerant cultivars, we compared deacclimation kinetics under controlled laboratory and field conditions among several blueberry genotypes with diverse genetic backgrounds. Clear genotypic differences in timing and rate of deacclimation were found. In the field study, the species Vaccinium constablaei Gray was identified as particularly late to deacclimate, and 'Little Giant' (50:50 hybrid of $V$. constablaei and $V$. ashei Reade) was nearly as late to deacclimate as $100 \% \mathrm{~V}$. constablaei. Recently, we extended our cold tolerance measurements from October through midwinter comparing acclimation kinetics and maximum cold tolerance levels among genotypes. Although all genotypes appeared to reach maximum cold tolerance about mid-December under the study conditions, genotypic differences were detected in other aspects, including initial cold tolerance, rate of acclimation, maximum cold tolerance, and length of the plateau. 'Little Giant' and 'Northsky' (75:25 hybrid of $V$. corymbosum $L$. and $V$. angustifolium Ait.) were very early to acclimate and were hardier than the other genotypes both initially and when maximum cold tolerance was reached. Understanding how cold tolerance levels change throughout the dormant period should help us to develop cultivars better suited to their environments.
\end{abstract}

In preparation for winter, woody perennial plants of the temperate zone have evolved mechanisms to first enter a state of dormancy in late summer or early fall and then, as fall progresses, to develop cold hardiness. The development of cold hardiness, termed cold acclimation, is triggered by environmental stimuli of shortening daylength and declining temperatures (Powell, 1987; Sakai and Larcher, 1987; Weiser, 1970). A plant's ability to survive low temperatures is dependent on several complex interacting factors. They include the timing of dormancy induction in the summer, the timing and rate of cold acclimation in the fall, the level of freezing tolerance reached while plants are in the cold-acclimated state, the maintenance of freezing tolerance during the winter, and the timing and rate of deacclimation and budbreak in the early spring, among others (Wisniewski et al., 2003). How these factors are controlled physiologically and genetically in woody perennials is not well understood.

The United States is the world's leading producer of blueberries. In a survey of blueberry research and extension scientists in

Received for publication 10 Dec. 2007. Accepted for publication $10 \mathrm{Jan} .2008$.

${ }^{1}$ To whom reprint requests should be addressed; e-mail Jeannine.Rowland@ars.usda.gov the United States, lack of winter hardiness and susceptibility to spring frosts were identified as two of the most important genetic limitations of current cultivars (Moore, 1993). In nearly all blueberry growing areas in the United States, economic losses from early spring frosts can be significant. In the northern production regions, winter damage is considered the major factor limiting yields (Hanson and Hancock, 1990; Moore, 1994). In the Pacific Northwest, drastic drops in temperature in the fall to below freezing can cause flower bud damage in some crops, including blueberry (Doughty and Hemerick, 1975) and grape (Davenport and Keller, in press). As blueberry germplasm becomes more diverse, there is increased concern whether resulting selections and cultivars are sufficiently cold hardy for certain regions of the country, especially if southern-adapted germplasm comprises a significant part of the genetic background as it does for some of the newer releases (Ehlenfeldt et al., 2006).

To develop blueberry cultivars for specific regions of the country, a comprehensive understanding of blueberry cold hardiness is needed. Ideally, a blueberry cultivar should acclimate to cold quickly in the fall, have a high midwinter hardiness (actual level dependent on where the cultivar is to be grown), and deacclimate slowly during spring or during unseasonably warm spells in winter without adversely affecting the time of fruit- ing (Arora et al., 2004). Therefore, in recent years, we have begun comparing patterns of acclimation, deacclimation, and maximum midwinter cold hardiness of flower buds for several different genotypes with diverse genetic backgrounds (Table 1). A summary of this work and our conclusions from it are described subsequently.

\section{MIDWINTER HARDINESS \\ AND DEACCLIMATION UNDER CONSTANT, WARM TEMPERATURES}

To determine if there are differences in the rate of deacclimation among genotypes that could be exploited for breeding more spring frost-tolerant cultivars, we initially examined the midwinter hardiness and rate of deacclimation among several blueberry cultivars under constant warm temperatures (Arora et al., 2004). Shoots were cut from field plants from a variety of genotypes midFebruary and placed in flasks of water in the laboratory at $\approx 20{ }^{\circ} \mathrm{C}$ to trigger deacclimation. The first year (2000) cold-hardiness levels were determined every $3 \mathrm{~d}$ of deacclimation (DOD) over a 2 -week period $(0,3,6$, $9,12,16$ DOD). Because of the rapid rate of deacclimation, however, the second year (2001) cold-hardiness levels were determined every day for $6 \mathrm{~d}(0,1,2,3,4,5,6$ DOD). Bud cold-hardiness levels (BCH) 
were determined as we have described previously using our freeze-thaw protocol (Arora et al., 2004; Rowland et al., 2005). After freezing, buds were dissected and observed for injury (visual browning) of the ovaries in individual flowers. For example, Figure 1 shows a longitudinal section of a flower bud of highbush blueberry that was damaged by freezing. Buds were rated for browning and $\mathrm{BCH}$ defined as the temperature causing $50 \%$ injury $\left(\mathrm{LT}_{50}\right)$.

Generally, the statistical analysis of $\mathrm{BCH}$ data were as follows. For each genotype by year combination, bootstrap estimates of $\mathrm{LT}_{50}$ values and their $95 \%$ fiducial confidence intervals were calculated across the days of deacclimation using Proc Probit (SAS Institute, 1999). Nine observed data points (three proximal buds on each of three shoots) for each temperature were resampled $(n=9$ with replacement) 30 times. A sigmoidal regression model was fit to percentage of injury (browning) versus treatment temperature for each of the 30 sets of resampled data. The 30 resulting values of $\mathrm{LT}_{50}$ and lower and upper confidence limits were averaged to obtain the bootstrap estimates at each DOD. The $\mathrm{LT}_{50}$ estimates were used to evaluate the deacclimation kinetics for each genotype by fitting a log-linear or asymmetrical sigmoidal (Gompertz) model, depending on the best fit for each genotype, to model the relationship between $\mathrm{LT}_{50}$ and days of deacclimation. The $\mathrm{LT}_{50}$ estimates from the models at each day of deacclimation and the differences in $\mathrm{LT}_{50}$ values between subsequent days were compared among genotypes using analysis of covariance (Milliken and Johnson, 2002).

Log-linear deacclimation models, fitted to the $\mathrm{BCH}$ versus DOD data, for two genotypes, 'Bluecrop' and 'Tifblue', in the 2000 pilot study are shown in Figure 2A. The largest loss in $\mathrm{BCH}$ and, thus, the fastest rate of deacclimation occurred in the first three DOD for both genotypes. During this time interval, the $V$. ashei (southern species) genotype 'Tifblue' lost significantly more of its initial $\mathrm{BCH}, 11.2{ }^{\circ} \mathrm{C}$ or $\approx 51 \%$, than did the $V$. corymbosum genotype 'Bluecrop', which lost $\approx 8.6{ }^{\circ} \mathrm{C}$ or $\approx 33 \%$ of its initial value. Therefore, the earliest and the faster deacclimator, during this first 3-d interval, was 'Tifblue'. 'Tifblue' was also the more cold-sensitive initially of the two genotypes with a midwinter cold-hardiness level of $\approx-20{ }^{\circ} \mathrm{C}$ as compared with $-25.4{ }^{\circ} \mathrm{C}$ for 'Bluecrop' (Table 1). Deacclimation rates for both genotypes slowed as they reached a $\mathrm{BCH}$ level of $\approx-11$ to $-13{ }^{\circ} \mathrm{C}$.

Overall, deacclimation occurred quickly at $20{ }^{\circ} \mathrm{C}$ and appeared to plateau for both genotypes by $\approx 6$ DOD. Therefore, the deacclimation study undertaken in 2001, which included more genotypes, focused on this critical 6-d period. In Figure 2B, log-linear or Gompertz deacclimation models, depending on the best fit for each genotype, fitted to the $\mathrm{BCH}$ versus DOD data, for three genotypes, 'Bluecrop', 'Tifblue', and 'Legacy', are shown. By 1 DOD, 'Tifblue' had lost the most $\mathrm{BCH}$, decreasing $5.7^{\circ} \mathrm{C}$, making it the

Table 1. Midwinter bud cold hardiness and germplasm composition of Vaccinium genotypes evaluated for timing and rate of deacclimation. ${ }^{z y}$

\begin{tabular}{|c|c|c|c|c|c|c|}
\hline \multirow{2}{*}{\multicolumn{2}{|c|}{ Bud cold hardiness $\left(\mathrm{LT}_{50}\right)^{\mathrm{x}}$}} & \multicolumn{5}{|c|}{ Germplasm composition $(\%)^{\mathrm{w}}$} \\
\hline & & \multicolumn{3}{|c|}{ Cold hardy species } & \multicolumn{2}{|c|}{ Cold sensitive species } \\
\hline Genotype & & $\overline{\text { V.cor. }} \mathrm{v}^{\mathrm{v}}$ & V. ang. & V.con. & V. dar. & V. ash. \\
\hline Bluecrop & $-25.4^{\circ} \mathrm{C}$ & 94 & 6 & - & - & - \\
\hline Legacy & $-16.0^{\circ} \mathrm{C}$ & 73 & 2 & - & 25 & - \\
\hline Little Giant & $<-28.0^{\circ} \mathrm{C}$ & - & - & 50 & - & 50 \\
\hline Northsky & $-28.4{ }^{\circ} \mathrm{C}$ & 73 & 27 & - & - & - \\
\hline Tifblue & $-20.0^{\circ} \mathrm{C}$ & - & - & - & - & 100 \\
\hline V. constablaei & $<-28.0^{\circ} \mathrm{C}$ & - & - & 100 & - & - \\
\hline
\end{tabular}

Rowland et al., 2005.

${ }^{y}$ All but pure $V$. constablaei were also evaluated for timing and rate of cold acclimation.

${ }^{x}$ Bud cold hardiness defined as temperature causing $50 \%$ injury or lethal temperature ${ }_{50}$ from our freezethaw protocol (Rowland et al., 2005).

${ }^{\text {w} A c c o r d i n g ~ t o ~ C l a r k ~ e t ~ a l . ~(1996), ~ E h l e n f e l d t ~(1994), ~ a n d ~ H a n c o c k ~ a n d ~ S i e f k e r ~(1982) . ~}$

${ }^{\mathrm{v}} V$. cor. $=V$. corymbosum; $V$. ang. $=V$. angustifolium; $V$. con. $=V$. constablaei; $V$. dar. $=V$. darrowi; $V$. ash. $=V$. ashei.

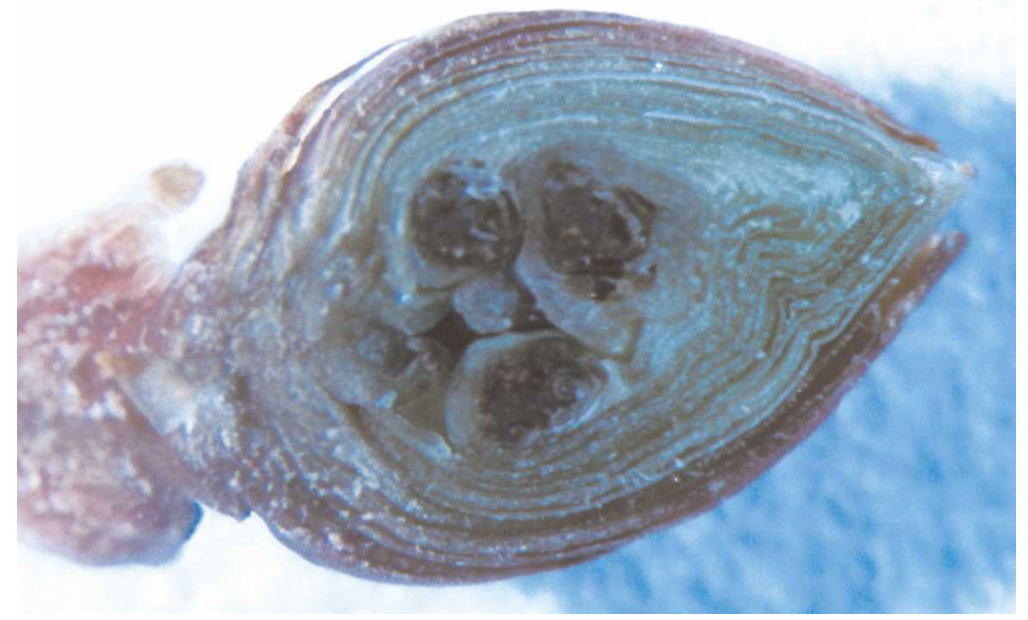

Fig. 1. Longitudinal section of a flower bud of the $V$. corymbosum cultivar Duke that was frozen at $-28{ }^{\circ} \mathrm{C}$ using our freeze-thaw protocol (Rowland et al., 2005). The black color indicates the flowers were killed.

earliest and fastest deacclimator of the three for the first time interval. By 2 DOD, its rate of deacclimation slowed considerably. By 1 DOD, 'Bluecrop' had changed the least, losing less than $1{ }^{\circ} \mathrm{C}$ of $\mathrm{BCH}$, making it the slowest deacclimator. By 2 DOD, however, its deacclimation had begun, and it continued to lose 2.2 to $2.6^{\circ} \mathrm{C}$ of $\mathrm{BCH}$ each day for the next $3 \mathrm{~d}$, at which point its rate of deacclimation slowed. 'Legacy' was an intermediate deacclimator, losing $2.3^{\circ} \mathrm{C}$ of BCH by $1 \mathrm{DOD}$.

\section{COLD HARDINESS AND DEACCLIMATION UNDER FIELD CONDITIONS}

From the previous studies, differences in deacclimation response were clearly evident among the cultivars, with 'Tifblue', the $V$. ashei genotype, being the earliest deacclimator under controlled laboratory conditions of constant $20^{\circ} \mathrm{C}$. Next, we wanted to try to compare deacclimation kinetics among more genotypes under natural field conditions of fluctuating temperatures. Although riskier than the controlled laboratory experiment, because flower buds can suffer freeze dam- age in the field before shoots are cut and frozen in the laboratory, we were successful at comparing deacclimation kinetics of a variety of genotypes over 2 years (Rowland et al., 2005).

For these experiments, shoots were cut from genotypes at weekly intervals in the field. The time we began cutting shoots depended on the weather conditions. The first year (2002), because it was a mild winter, we thought buds might begin to deacclimate fairly early; hence, shoots were cut beginning at the end of January and ending in April. The second year (2003), because it was a much colder winter, shoots were not cut until the beginning of March. Although sampling was begun approximately a month earlier in 2002 than in 2003, a detectable loss in BCH (more positive $\mathrm{LT}_{50} \mathrm{~s}$ ) did not occur until sometime between Week 4 (19 Feb. 2002) and Week 5 (26 Feb. 2002). This was only slightly earlier than in 2003 when a detectable loss in $\mathrm{BCH}$ occurred sometime between Week 1 (4 Mar. 2003) and Week 2 (11 Mar. 2003). When the data from the 2 years were aligned and superimposed, beginning with the date before deacclimation began and continuing through 

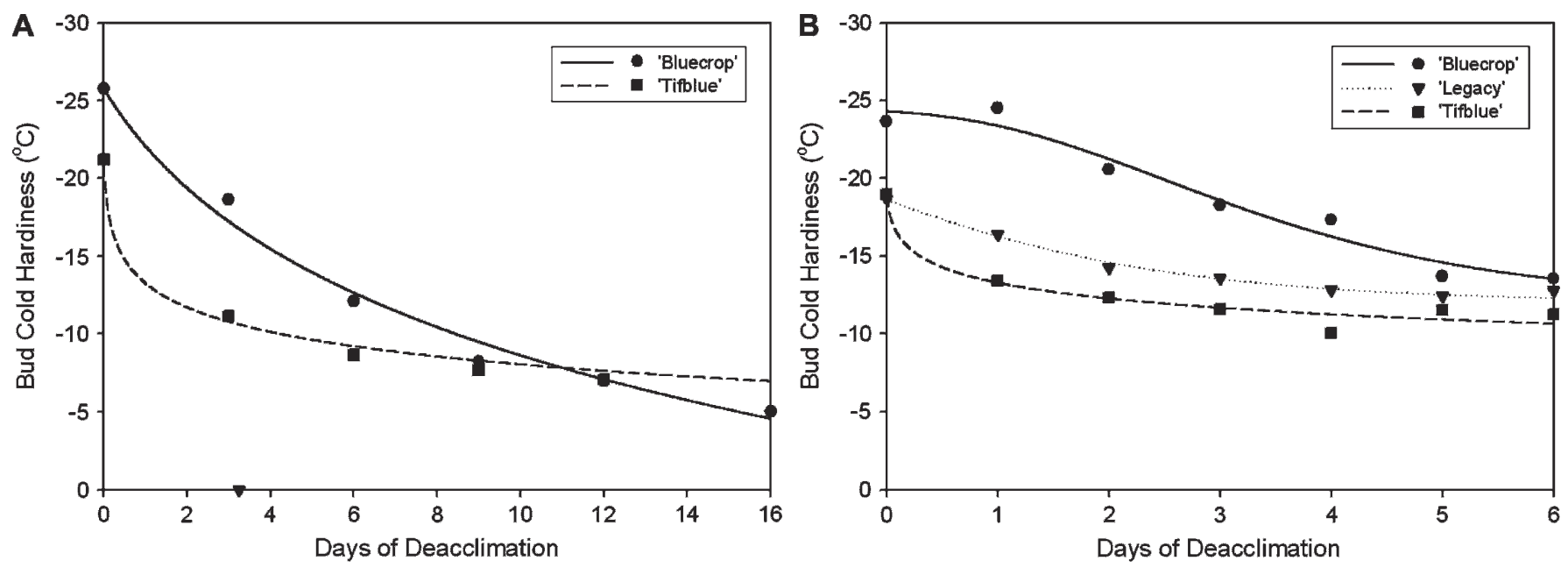

Fig. 2. (A) Deacclimation of two blueberry cultivars, 'Bluecrop' and 'Tifblue' from 0 DOD (days of deacclimation) through 16 DOD under controlled laboratory conditions in 2000 (Arora et al., 2004). Curves show the bud cold hardiness (BCH) values predicted from log-linear models. Points represent observed values. (B) Deacclimation of three blueberry cultivars (Bluecrop, Legacy, and Tifblue) from 0 DOD through 6 DOD under controlled laboratory conditions in 2001 (Arora et al., 2004). Curves show the BCH values predicted from log-linear ('Tifblue') or Gompertz ('Bluecrop' and 'Legacy') models. Points represent observed values.

to approximately mid-April (Weeks 4 to 10 in 2002/19 Feb. to 9 Apr. and Weeks 1 to 7 in 2003/4 Mar. to 15 Apr.), remarkably similar $\mathrm{BCH}$ levels were found between years. Consequently, $\mathrm{BCH}$ data from Weeks 4 to 10 of year 2002 and Weeks 1 to 7 of year 2003 were combined and averaged and are hereafter referred to as Weeks 1 to 7 of the combined-year study.

The statistical analysis of $\mathrm{BCH}$ data were carried out as described previously for the controlled laboratory experiments, except that $\mathrm{BCH}$ here was monitored at weekly intervals rather than every $3 \mathrm{~d}$ or daily. Gompertz deacclimation models, fitted to the $\mathrm{BCH}$ versus weeks of deacclimation data for the combined-year study for six of the 12 genotypes that were evaluated, are shown in Figure 3. There were clear genotypic differences in initial BCH levels. Of the genotypes shown, 'Legacy', which is three-fourths $V$. corymbosum and one-fourth the southern species $V$. darrowi Camp, was the least cold hardy at initial evaluation, even less so than 'Tifblue' (100\% southern species $V$. ashei). 'Legacy' had an $\mathrm{LT}_{50}$ of $-16{ }^{\circ} \mathrm{C}$, whereas 'Tifblue' was hardy to $-20{ }^{\circ} \mathrm{C}$ (Table 1; Fig. 3 ). 'Bluecrop' (predominantly $V$. corymbosum) was intermediate in $\mathrm{BCH}$ with an $\mathrm{LT}_{50}$ of $-25.4{ }^{\circ} \mathrm{C}$. Pure $V$. constablaei, 'Little Giant', which is half $V$. constablaei and half $V$. ashei, and 'Northsky', which is threefourths $V$. corymbosum and one-fourth $V$. angustifolium, were the most cold hardy with $\mathrm{BCH}$ levels less than $-28{ }^{\circ} \mathrm{C}$, the lowest temperature that our glycol freezing bath would reach. $V$. corymbosum and $V$. angustifolium are northern highbush and lowbush species, respectively. $V$. constablaei is a highbush-like species that, although native to the southern United States, is found at high elevations in northern Georgia, western North Carolina, and eastern Tennessee.

Regarding deacclimation kinetics, the weekly intervals with the largest losses in

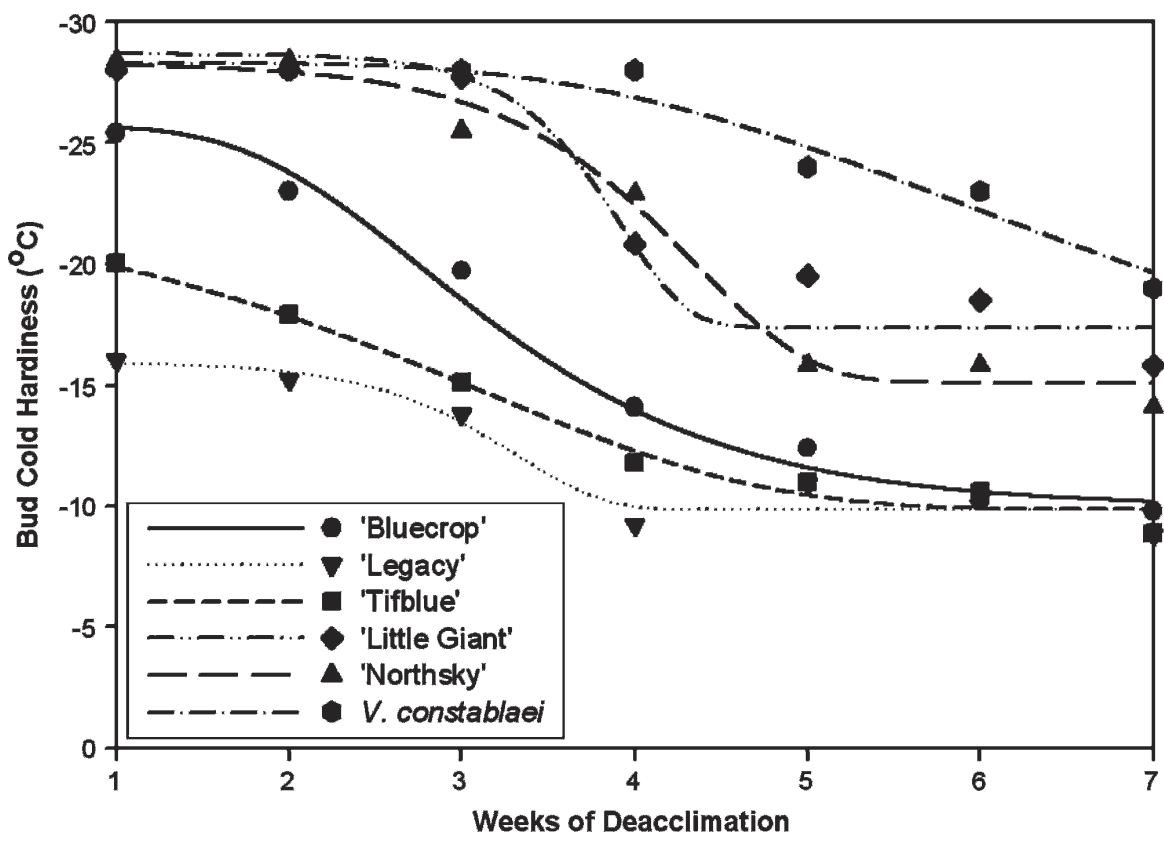

Fig. 3. Deacclimation of six blueberry genotypes ('Bluecrop', 'Legacy', 'Little Giant', 'Northsky', 'Tifblue', and $V$. constablaei selections) from 0 WOD (weeks of deacclimation) through 7 WOD under field conditions in the combined-year (2002 and 2003) study (Rowland et al., 2005). Curves show the $\mathrm{BCH}$ values predicted from Gompertz models. Points represent observed values.

$\mathrm{BCH}$ (i.e., highest rates of deacclimation) also varied among genotypes (Fig. 3). In the first 4 weeks, 'Tifblue' had a fairly constant rate of deacclimation, losing 2 to $3{ }^{\circ} \mathrm{C}$ of $\mathrm{BCH}$ per week, making it the earliest deacclimator of those shown. For 'Bluecrop' and 'Legacy', the greatest losses in $\mathrm{BCH}$ were observed at Weeks 3 and 4. For 'Little Giant' and 'Northsky', losses in BCH were greatest at Weeks 4 and 5, whereas for V. constablaei, losses were greatest at Weeks 6 and 7, making it the latest deacclimator. A comparison of timing of deacclimation with germplasm composition indicated that, like in the controlled laboratory study, $V$. ashei was particularly early to deacclimate. Vaccinium constablaei, which was not studied previously, was particularly late to deacclimate, and 'Little Giant', a 50:50 hybrid of $V$. constablaei and $V$. ashei, was nearly as late to deacclimate as the $100 \% \mathrm{~V}$. constablaei selections. From this work, we concluded that $V$. constablaei may be useful in breeding programs to contribute genes for late deacclimation, which should translate into greater spring frost tolerance in addition to contributing genes for midwinter hardiness.

To determine if the stage of bud opening could be used as an indicator of the level of $\mathrm{BCH}$, we examined bud opening in the 
progressively deacclimating flower buds of the various genotypes in the field study. At each weekly sampling for $\mathrm{BCH}$, several shoots, with five to eight floral buds each, were evaluated for stage of bud opening. Stages were ranked on the scale of 1 to 7 as described by Spiers (1978), with 1 representing the stage with no visible swelling and 7 representing the stage after which corollas had completely expanded and dropped. Percentages of buds at stages 1 to 7 were recorded at each weekly sampling and from this, the average bud score for each week of deacclimation was calculated. Like $\mathrm{BCH}$ data, flower bud development scores from Weeks 4 to 10 of year 2002 were averaged with scores from Weeks 1 to 7 of year 2003 . At Week 1 of the combined-year study, flower buds of all genotypes were fairly tightly closed (average bud stage of 1.0 to 1.5 ). They became progressively more developed during the deacclimation regime, reaching stages of 2.3 to 4.0 by Week 7 for all genotypes except V. constablaei and 'Little Giant', which remained in the 1.0 to 1.5 range. The correlation between bud opening (average bud score) and $\mathrm{BCH}$ values was determined using SAS Proc CORR (SAS Institute, 1999). A highly significant positive correlation was found between the stage of bud opening scores and $\mathrm{BCH}$ averaged over the 2 years $(r=0.84, P<0.0001)$. Figure 4 shows a plot of $\mathrm{BCH}$ level versus stage of bud opening.

\section{RATE OF COLD ACCLIMATION UNDER FIELD CONDITIONS}

In a more recent study, we extended our cold tolerance measurements from October through midwinter comparing acclimation kinetics and maximum cold tolerance levels among several blueberry genotypes. For these experiments, shoots were cut from genotypes every 3 weeks in the field and $\mathrm{BCH}$ levels determined as described previously calculating $\mathrm{LT}_{50}$ values and their lower and upper confidence limits. We currently have only 1 -year's data. The $\mathrm{BCH}$ results from this year, 17 Oct. 2006 to 10 Jan. 2007, are shown in Figure 5 for five of the genotypes that were analyzed.

All the genotypes appeared to reach maximum cold tolerance $\approx 20$ Dec. 2006 , but genotypic differences were detected in other aspects, including initial cold tolerance, rate of acclimation, maximum cold tolerance, and length of the plateau. From these preliminary results, it appears that 'Tifblue' was the least cold hardy initially followed by 'Legacy', 'Bluecrop', 'Little Giant', and 'Northsky'. 'Northsky' was already cold hardy to less than $-22^{\circ} \mathrm{C}$ (the lowest temperature that was tested at the first time point) on 17 Oct., making it the earliest acclimator. Of the time points that were analyzed, however, 'Little Giant' appeared to acclimate the fastest (i.e., its line had the steepest slope at the early time points). By 20 Dec., when maximum cold tolerance was reached, the most hardy cultivars were Little Giant and Northsky $\left(\mathrm{LT}_{50} \mathrm{~s}\right.$ less than $-28{ }^{\circ} \mathrm{C}$ ) followed in descending

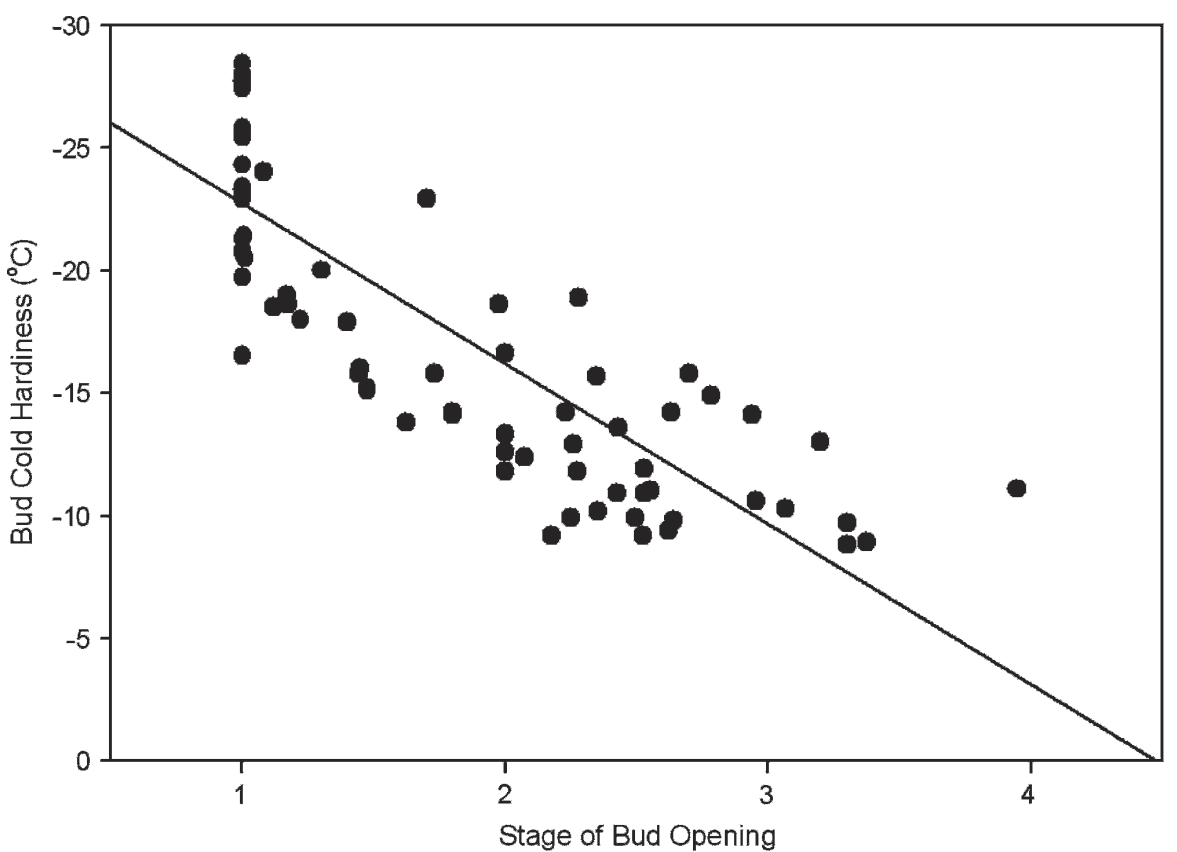

Fig. 4. Graph of bud cold hardiness levels versus average stage of bud opening for the blueberry genotypes in the combined-year (2002 and 2003) field study.

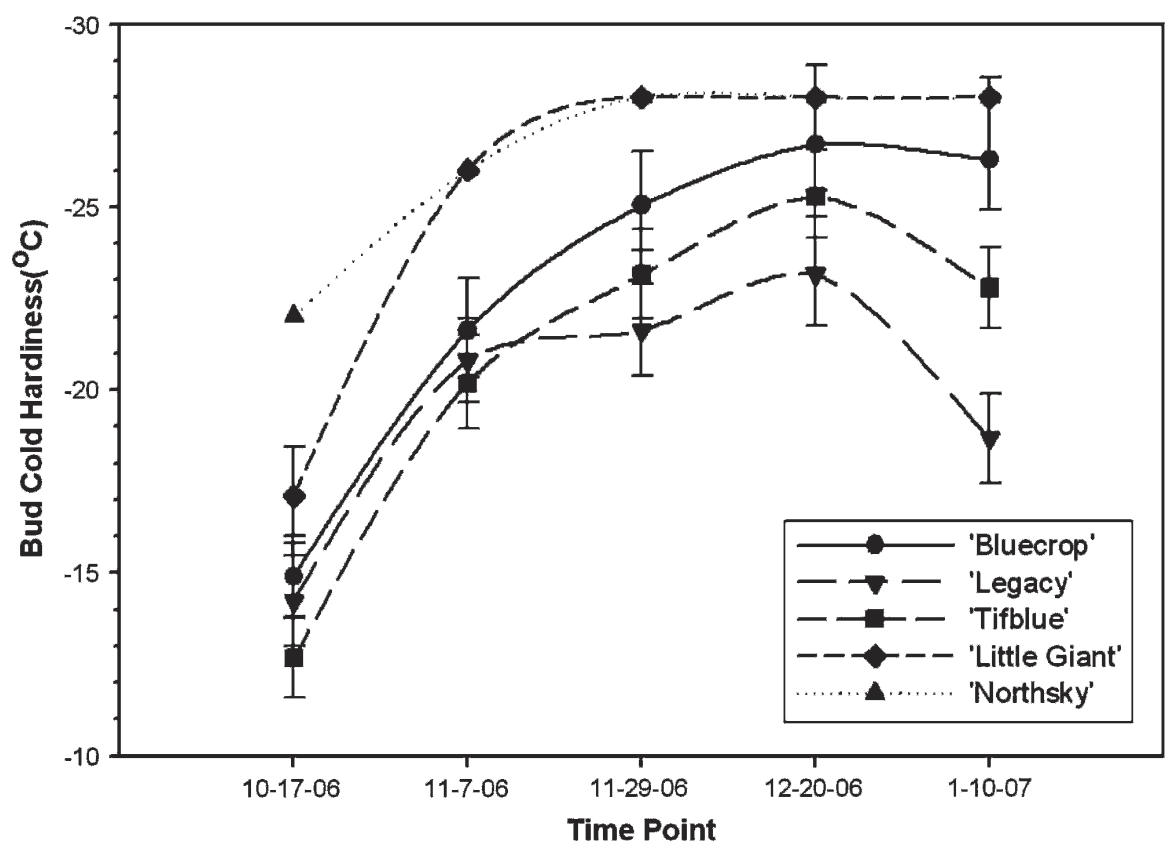

Fig. 5. Acclimation of five blueberry genotypes ('Bluecrop', 'Legacy', 'Little Giant', 'Northsky', and 'Tifblue') under field conditions. Lines show the bud cold hardiness values determined at 3-week intervals from 17 Oct. 2006 through 10 Jan. 2007. Points are the actual observed values and the bars represent the $95 \%$ fiducial confidence limits.

order by 'Bluecrop', 'Tifblue', and 'Legacy'. Surprisingly, by 10 Jan. 2007, the least hardy cultivars, Tifblue and Legacy, had already begun to deacclimate, having lost $\approx 2.5$ and $4.5^{\circ} \mathrm{C}$ of $\mathrm{BCH}$, respectively, when compared with their maximum cold tolerance levels on 20 Dec. Deacclimation was not detected this early in our previous study (in 2002) when $\mathrm{BCH}$ levels were determined at weekly intervals beginning in January. It will be of interest to see when deacclimation begins for these two cultivars in 2008. An examina- tion of the weather data revealed that November and December of 2006 were the warmest on record since 1895 . The first $20 \mathrm{~d}$ of 2007 Jan. were also unusually warm, although temperatures cooled considerably by the end of January. Still, 2007 Jan. was $6.4^{\circ} \mathrm{F}$ higher than average and the 11th warmest since 1895 . Thus, the unusually warm early winter weather must have triggered deacclimation in the least hardy cultivars. $\mathrm{BCH}$ levels for the hardier 'Bluecrop', however, did not change significantly between the 
December and January sampling dates. Because 'Little Giant' and 'Northsky' were both hardy to less than $-28{ }^{\circ} \mathrm{C}$ (the limit of this method) at these sampling dates, it is impossible to determine whether there was a small drop in hardiness of either of these.

\section{CONCLUSIONS}

Injury to blueberry buds can be caused by fall frosts as plants are cold acclimating or by spring frosts as plants are deacclimating. In the winter, fully acclimated buds can be injured by sustained freezing temperatures. To develop blueberry cultivars for specific regions of the country, a comprehensive understanding of cold hardiness is needed throughout the dormant period from acclimation to deacclimation. In earlier studies, to identify genotypes that are particularly slow or late to deacclimate and thus may be useful in breeding for spring frost-tolerant cultivars, we compared deacclimation kinetics under controlled laboratory (constant temperature) and field conditions among several blueberry genotypes with diverse genetic backgrounds. Clear genotypic differences were found. In the field study, pure $V$. constablaei selections and 'Little Giant', a 50:50 hybrid of $V$. constablaei and $V$. ashei, were particularly late to deacclimate compared with the other genotypes. In the laboratory and field study, 'Tifblue', a $100 \%$ V. ashei cultivar, was particularly early to deacclimate. In addition, we found a strong positive correlation between stage of bud opening and coldhardiness level, suggesting that for many genotypes, stage of bud opening could be used as an indicator of cold hardiness in the progressively deacclimating buds. More recently, we have extended our cold tolerance measurements from October through midwinter comparing acclimation kinetics and maximum cold tolerance levels among blueberry genotypes. Genotypic differences were detected in many aspects, including initial cold tolerance, rate of acclimation, maximum cold tolerance, and length of the plateau. 'Little Giant' and 'Northsky', a 75:25 hybrid of $V$. corymbosum and $V$. angustifolium, were very early to acclimate and were hardier than the other genotypes both initially and when maximum cold tolerance was reached. 'Bluecrop', the industry standard for many areas of the country, was intermediate in terms of its rate of acclimation and deacclimation and maximum cold tolerance level. For the most part, the rates of acclimation and deacclimation and midwinter cold tolerance levels of the genotypes were not surprising considering the natural habitat of the species comprising their genetic background, except perhaps for 'Little Giant' which, although a 50:50 hybrid of $V$. constablaei and $V$. ashei, was nearly as hardy and slow to deacclimate as pure $V$. constablaei.

\section{Literature Cited}

Arora, R., L.J. Rowland, E.L. Ogden, A.L. Dhanaraj, C.O. Marian, M.K. Ehlenfeldt, and B. Vinyard. 2004. Dehardening kinetics, bud development, and dehydrin metabolism in blueberry cultivars during deacclimation at constant, warm temperatures. J. Amer. Soc. Hort. Sci. 129:667-674.

Clark, J.R., J.N. Moore, and A.D. Draper. 1996. 'Ozarkblue' southern highbush blueberry. HortScience 31:1043-1045.

Davenport, J. and M. Keller. How cold can you go? Frost and winter protection for grape. HortScience 43:1966-1969.

Doughty, C.C. and G.A. Hemerick. 1975. Impedance as a measurement of blueberry bud hardiness. J. Amer. Soc. Hort. Sci. 100:115-118.
Ehlenfeldt, M.K. 1994. The genetic composition and tetrasomic inbreeding coefficients of highbush blueberry cultivars. HortScience 29:1342-1345.

Ehlenfeldt, M.K., E.L. Ogden, L.J. Rowland, and B. Vinyard. 2006. Evaluation of midwinter cold hardiness among 25 rabbiteye blueberry cultivars. HortScience 41:579-581.

Hancock, J.F. and J.H. Siefker. 1982. Levels of inbreeding in highbush blueberry cultivars. HortScience 17:363-366.

Hanson, E.J. and J.F. Hancock. 1990. Highbush blueberry cultivars and production trends. Fruit Var. J. 44:77-81.

Milliken, G.A. and D.E. Johnson. 2002. Analysis of messy data-Volume III: Analysis of covariance. Chapman \& Hall/CRC, London, UK.

Moore, J.N. 1993. The blueberry industry of North America. Acta Hort. 346:15-26.

Moore, J.N. 1994. The blueberry industry of North America. HortTechnology 4:96-102.

Powell, L.E. 1987. Hormonal aspects of bud and seed dormancy in temperate-zone woody plants. HortScience 22:845-850.

Rowland, L.J., E.L. Ogden, M.K. Ehlenfeldt, and B. Vinyard. 2005. Cold hardiness, deacclimation kinetics, and bud development among 12 diverse blueberry genotypes under field conditions. J. Amer. Soc. Hort. Sci. 130:508-514.

Sakai, A. and W. Larcher. 1987. Frost survival of plants: Responses and adaptation to freezing stress. Springer, Berlin, Heidelberg, New York.

SAS Institute. 1999. SAS/STAT user's guide. Release 8.0. SAS Institute, Cary, NC.

Spiers, J.M. 1978. Effect of stage of bud development on cold injury in rabbiteye blueberry. J. Amer. Soc. Hort. Sci. 103:452-455.

Weiser, C.J. 1970. Cold resistance and injury in woody plants. Science 169:1269-1278.

Wisniewski, M., C. Bassett, and L.V. Gusta. 2003. An overview of cold hardiness in woody plants: Seeing the forest through the trees. HortScience 38:952-959. 